ORNL/TM-2019/1251

\title{
Post-Irradiation Examination of High Fluence Baffle-Former Bolts Retrieved from a Westinghouse Two-Loop Downflow Type PWR
}

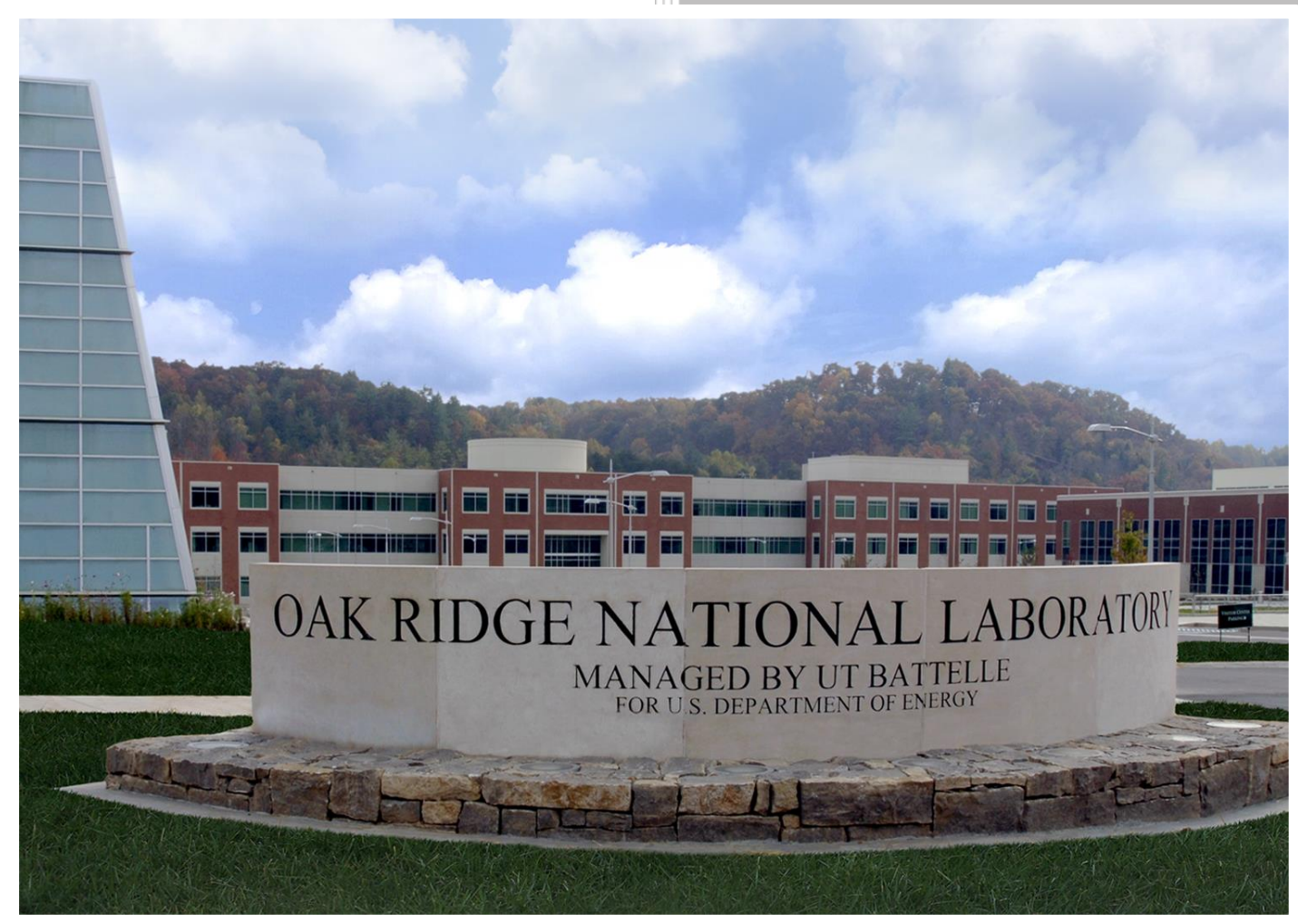

X. Chen ${ }^{1}$, T. Chen ${ }^{1 *}$, C.M. Parish ${ }^{1}$, T. Graening ${ }^{1 * *}$, M.A. Sokolov ${ }^{1}$, K.J. Leonard ${ }^{1 *}$

${ }^{1}$ Oak Ridge National Laboratory * Former employee of ORNL * Visiting scholar at ORNL

July 31, 2019 


\section{DOCUMENT AVAILABILITY}

Reports produced after January 1, 1996, are generally available free via US Department of Energy (DOE) SciTech Connect.

\section{Website www.osti.gov}

Reports produced before January 1, 1996, may be purchased by members of the public from the following source:

National Technical Information Service

5285 Port Royal Road

Springfield, VA 22161

Telephone 703-605-6000 (1-800-553-6847)

TDD 703-487-4639

Fax 703-605-6900

E-mailinfo@ntis.gov

Website http://classic.ntis.gov/

Reports are available to DOE employees, DOE contractors, Energy Technology Data Exchange representatives, and International Nuclear Information System representatives from the following source:

Office of Scientific and Technical Information

PO Box 62

Oak Ridge, TN 37831

Telephone 865-576-8401

Fax 865-576-5728

E-mail reports@osti.gov

Website http://www.osti.gov/contact.html

This report was prepared as an account of work sponsored by an
agency of the United States Government. Neither the United States
Government nor any agency thereof, nor any of their employees, makes
any warranty, express or implied, or assumes any legal liability or
responsibility for the accuracy, completeness, or usefulness of any
information, apparatus, product, or process disclosed, or represents that
its use would not infringe privately owned rights. Reference herein to
any specific commercial product, process, or service by trade name,
trademark, manufacturer, or otherwise, does not necessarily constitute
or imply its endorsement, recommendation, or favoring by the United
States Government or any agency thereof. The views and opinions of
authors expressed herein do not necessarily state or reflect those of the
United States Government or any agency thereof.




\title{
POST-IRRADIATION EXAMINATION OF HIGH FLUENCE BAFFLE- FORMER BOLTS RETRIEVED FROM A WESTINGHOUSE TWO- LOOP DOWNFLOW TYPE PWR
}

\author{
Xiang (Frank) Chen ${ }^{1}$, Tianyi Chen ${ }^{1 *}$, Chad M. Parish${ }^{1}$, Tim Graening ${ }^{1 * *}$, Mikhail A. \\ Sokolov ${ }^{1}$, Keith J. Leonard ${ }^{1 *}$ \\ ${ }^{1}$ Oak Ridge National Laboratory \\ * Former employee of Oak Ridge National Laboratory \\ ** Visiting scholar at Oak Ridge National Laboratory
}

Date Published: July 31, 2019

Prepared under the direction of the

U.S. Department of Energy

Office of Nuclear Energy

Light Water Reactor Sustainability

Materials Research Pathway

Prepared by

OAK RIDGE NATIONAL LABORATORY

Oak Ridge, Tennessee 37831

managed by

UT-BATTELLE, LLC

for the

U.S. DEPARTMENT OF ENERGY

under contract DE-AC05-00OR22725 
This page intentionally left blank 


\section{CONTENTS}

Page

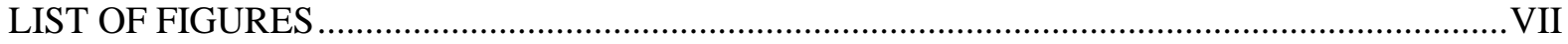

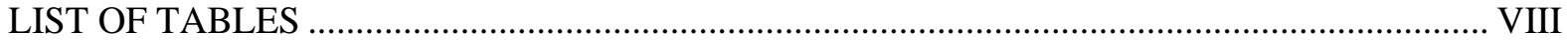

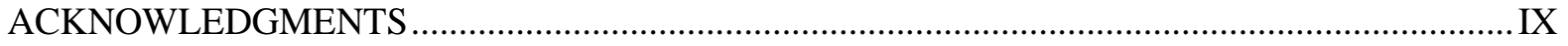

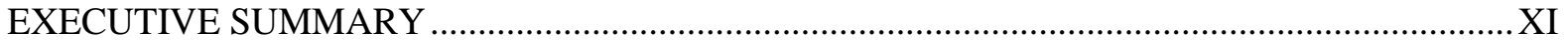

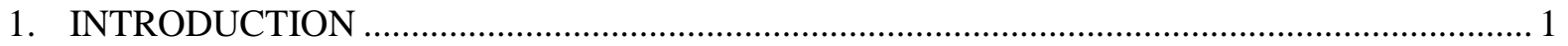

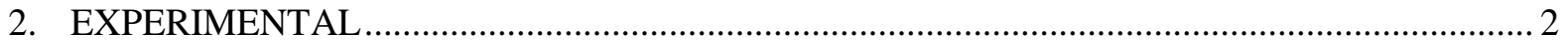

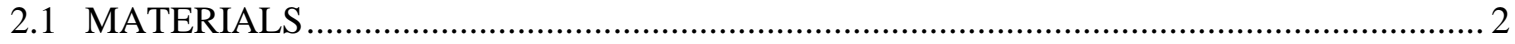

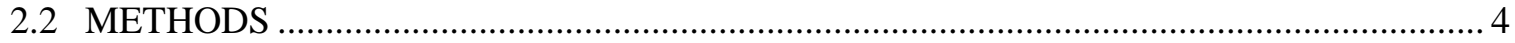

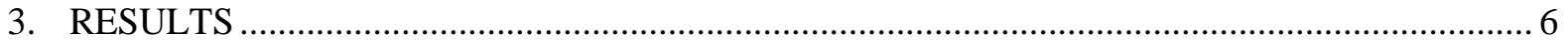

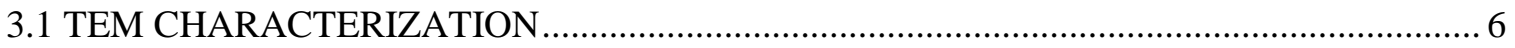

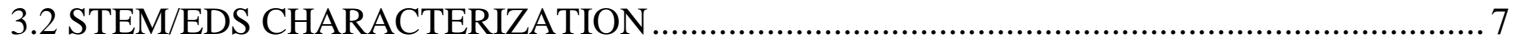

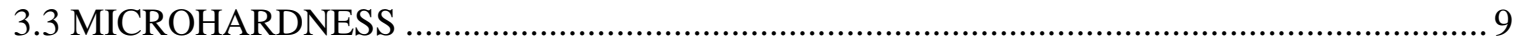

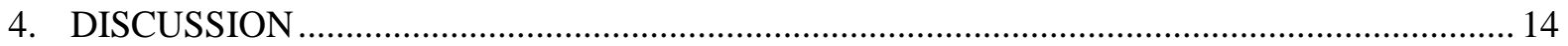

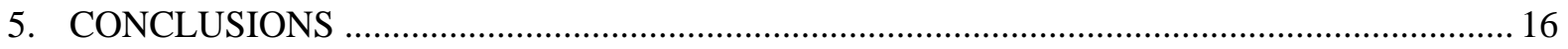

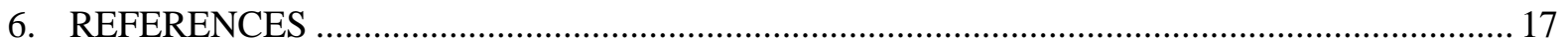


This page intentionally left blank 


\section{LIST OF FIGURES}

Figure

Page

Figure 2.1 Images of bolt heads for bolt \#4412 in (a) and bolt \#4416 in (b) [4] ..................................2

Figure 2.2 Machining diagram for the BFBs showing the color-coded sample types (red: $0.5 \mathrm{~mm}$ slices, black: $1.0 \mathrm{~mm}$ slices, light orange: bend bars, and light blue: remaining collar materials) [5] ... 3 Figure 2.3 Schematic for sample IDs from machined BFBs [5] 4 Figure 2.4 Hardness measurement patterns for 4412 CS2 and 4416 CS2 in (a) and 4412 TBA, 4412 $\mathrm{BBA}, 4416 \mathrm{TBA}$, and $4416 \mathrm{BBA}$ in (b). At least three measurements were made at each marked location [4]

Figure 3.1 DF images of dislocation loops and their size distributions for 4416 CS1, MS, and BS samples presented in (a-b), (c-d), and (e-f), respectively 6 Figure 3.2 Cavities observed at an underfocused condition for the 4416 CS1 (a), MS (b), and BS (c) samples. Some of the cavities are marked with black arrows 7 Figure 3.3 STEM/EDS-based composition maps for the 4416 CS1 sample. Arrows point to a GB..... 8 Figure 3.4 STEM/EDS-based composition maps for the $4416 \mathrm{MS}$ sample. Arrows point to a GB....... 8 Figure 3.5 STEM/EDS-based composition maps showing Ni-Si precipitates in the 4416 BS sample .. 9 Figure 3.6 Segregation of P on the vertical GB, but not the horizontal GB of the 4416 CS1 sample.... 9 Figure 3.7 Microhardness maps for 4412 CS2 in (a) and 4416 CS2 in (b) 10 Figure 3.8 Microhardness maps for 4412 TBA in (a), 4412 BBA in (b), 4416 TBA in (c), and 4416 BBA in (d)

Figure 3.9 Statistics of microhardness measurements for bolts 4412 and 4416 


\section{LIST OF TABLES}

Table

Page

Table 2.1 Compositions of three heats of type 347 SS used for the construction of the reactor in comparison with material specification (wt $\%$ ) 3

Table 2.2 Fluence and displacement damage distributions for two retrieved BFBs ........................... 3

Table 2.3 IDs of specimens characterized in this study .................................................................

Table 3.1 Statistics of dislocation loops observed in TEM characterization of bolt 4416 .................... 6

Table 3.2 Statistics of cavities observed in TEM and the calculated swelling levels of bolt $4416 \ldots \ldots . .7$ 


\section{ACKNOWLEDGMENTS}

This research was sponsored by the U.S. Department of Energy, Office of Nuclear Energy, Light Water Reactor Sustainability Program, Materials Research Pathway, under contract DE-AC0500OR22725 with UT-Battelle, LLC/Oak Ridge National Laboratory. The authors wish to thank Thomas M. Rosseel and Keith J. Leonard who provided programmatic support for this project.

The authors extend their appreciation to Mark Delph, Clay Morris, and other team members at Irradiated Materials Examination and Testing Facility of Oak Ridge National Laboratory for their technical support. The authors would like to thank Mike Burke formerly of Westinghouse in sample preparation, machining, and shipping and Heather Malikowski of Exelon Generation, Robert Marcello of R.E. Ginna Nuclear Power Plant, and Bernard Rudell formerly of Exelon Generation - Corporate Asset Management for their roles in preserving and making the ex-service bolts available. Lastly, the authors are grateful for Dr. Lizhen Tan and Dr. Wei Tang for their technical review of this report. 
This page intentionally left blank 


\section{EXECUTIVE SUMMARY}

As one of the pressurized water reactor (PWR) internal components, baffle-former bolts (BFBs) are subjected to significant mechanical stress and neutron irradiation from the reactor core during the plant operation. Over the long operation period, these conditions lead to potential degradation and reduced load-carrying capacity of the bolts. In support of evaluating long-term operational performance of materials used in core internal components, the Oak Ridge National Laboratory (ORNL), through the Department of Energy (DOE), Light Water Reactor Sustainability (LWRS) Program, Materials Research Pathway (MRP) has harvested two high fluence BFBs from a commercial Westinghouse two-loop downflow type PWR. The two bolts of interest, i.e. bolts 4412 and 4416, were withdrawn from service in 2011 as part of a preventative replacement plan. No identification of cracking or potential damage was found for these bolts during their removal in 2011 . However, the bolts required a lower torque for removal from the baffle structure than the original torque specified during installation. Irradiation displacement damage levels in the bolts range from 15 to 41 displacements per atom. The goal of this project is to perform detailed microstructural and mechanical property characterization of BFBs following in-service exposures. The information from these bolts will be integral to the LWRS program initiatives in evaluating end of life microstructure and properties. Furthermore, valuable data will be obtained that can be incorporated into model predictions of long-term irradiation behavior and compared to results obtained in high flux experimental reactor conditions.

This report documents the completion of the post-irradiation examination of selected specimens from the two high fluence BFBs. Electron microscopy and microhardness characterization were performed. The radiation-induced defects in the material of this study are not considerably different from neutron-induced defects in 304/316 grades of stainless steels (SS). Results from this study fill the current knowledge gap in radiation-induced microstructure and mechanical property changes for type 347 austenitic SS after high fluence commercial PWR irradiation. Main findings of this study are:

1. Dislocation loops with average sizes in the range of 11-16 $\mathrm{nm}$ and number densities in the range of $3-5 \times 10^{22} / \mathrm{m}^{3}$ were observed from the retrieved BFB 4416 .

2. From bolt head to the end of the thread section, cavity size increased whereas the cavity number density decreased. The swelling of the BFB 4416 was insignificant with maximum swelling of less than $0.02 \%$.

3. Radiation-induced segregation (RIS) for BFB 4416 resulted in enrichment of Ni, Si, and P on grain boundaries but depletion of $\mathrm{Fe}, \mathrm{Cr}, \mathrm{Mn}$, and $\mathrm{S}$. In addition, Ni-Si clusters were observed in the matrix.

4. Radiation-induced microstructural features for BFB 4416 were more developed from the middle shank to the end of the thread section, e.g. larger dislocation loops, cavities, and coarser precipitates, indicating higher irradiation temperatures in those regions than in the bolt head.

5. Microhardness measurements did not show a clear effect of neutron fluence on hardness values or any specific spatial irradiation hardening pattern for BFBs 4412 and 4416. 
This page intentionally left blank 


\section{INTRODUCTION}

As one of the pressurized water reactor (PWR) internal components, baffle-former bolts (BFBs) are subjected to significant mechanical stress and neutron irradiation from the reactor core during the plant operation. Over the long operation period, these conditions lead to potential degradation and reduced load-carrying capacity of the bolts. The BFB has been a particular concern for the industry since the first observation of failed bolts following the investigation of flow-induced vibration of fuel rods in elements on the core periphery observed in French 900 MW plants in the 1980s [1]. In the United States, the first degraded BFBs were observed in 1999. In support of evaluating longterm operational performance of materials used in core internal components, the Light Water Reactor Sustainability (LWRS) Program has pursued the retrieval of aged structural components for the study of the microstructure, mechanical, and corrosion-related properties including stress corrosion cracking (SCC) and irradiation-assisted stress corrosion cracking (IASCC) initiation and growth. To this end, the program has actively worked over several years to retrieve high fluence BFBs.

In this work, the Oak Ridge National Laboratory (ORNL), through the U.S. Department of Energy (DOE) LWRS Program, has obtained specimens machined from two high fluence BFBs retrieved from a commercial Westinghouse two-loop downflow type PWR. The objective of this project is to provide information that is integral to evaluating end of life microstructure and properties as a benchmark of international models developed for predicting radiation-induced swelling, segregation, precipitation, and mechanical property degradation. In the initial study, electron microscopy characterization was performed on one of the two retrieved BFBs to evaluate radiation-induced damages, such as dislocation loops, cavities, segregation, precipitation, etc. In addition, microhardness measurements were performed from different regions of both bolts to evaluate the irradiation-induced hardening. Results from this study fill the current knowledge gap in radiation-induced microstructure and mechanical property changes for type 347 austenitic stainless steels (SS) after high fluence commercial PWR irradiation. 


\section{EXPERIMENTAL}

\subsection{MATERIALS}

The retrieved BFBs are two of the highest fluence bolts available from the original type 347 austenitic SS bolts used in the reactor. Both bolts showed no indication of cracking during the ultrasonic inspection and in visual inspection following removal from service. However, the bolts required a lower torque for removal from the baffle structure than the original torque specified during installation. Figure 2.1 shows images of the bolt heads of two retrieved BFBs. No indication of surface cracking was observed in the transition region between shaft and head, although some surface debris scale flaked off from the bolt body. The shiny portion of the bolt head was due to electric discharge machining when the bolts were removed from the baffle wall. The ID number for the bolts follows a 4-digit code with the first number being the quadrant location in the reactor, then the associated baffle plate number, the column location of the bolt associated with the particular baffle plate number, and finally the former plate location where the bolt originated. While the exact elemental compositions of the two retrieved BFBs were not available at the time of preparation of this report, Table 2.1 shows compositions of three heats of type 347 SS used for the construction of the reactor in comparison with the material specification. The compositions of all three heats met the type $347 \mathrm{SS}$ specification. Table 2.2 provides information on the range of fluences and estimated displacement damage along the length of the two bolts. The displacement damage values for the two bolts range from 15 to 41 displacements per atom (dpa) assuming a fluence to dpa conversion value of $6.7 \times 10^{20} \mathrm{n} / \mathrm{cm}^{2}, \mathrm{E}>1 \mathrm{MeV}$ per dpa [2]. Other important information for the two retrieved bolts not available at the time of preparation of this report includes the irradiation temperature profile and flux both of which require more complicated modeling and calculation and they can vary within each power cycle and from cycle to cycle. Nonetheless, calculations [3] from Point Beach Unit 2, which is another Westinghouse two-loop type PWR, showed that the irradiation temperature and flux for a BFB from a region next to the bolt 4416 studied in this work varied in the range of $323-344^{\circ} \mathrm{C}$ and $7.5 \times 10^{12}-1.8 \times 10^{13} \mathrm{n} / \mathrm{cm}^{2}-\mathrm{sec}(\mathrm{E}>1 \mathrm{MeV})$ along the length of the bolt, respectively. It is worth noting that Point beach Unit 2 was originally a Westinghouse downflow two-loop PWR, but was converted to upflow in Nov 1986 [3].
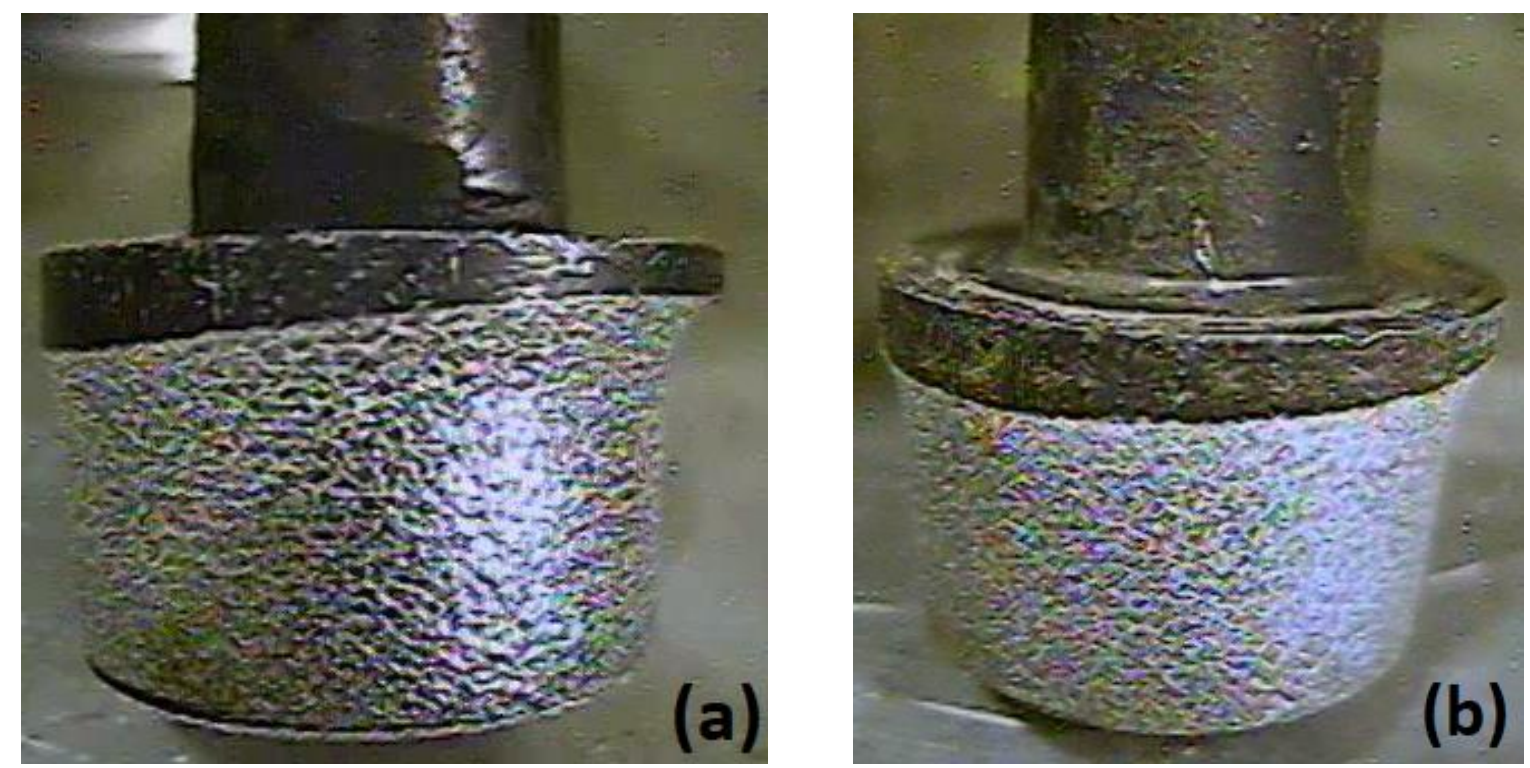

Figure 2.1 Images of bolt heads for bolt \#4412 in (a) and bolt \#4416 in (b) [4] 
Table 2.1 Compositions of three heats of type 347 SS used for the construction of the reactor in comparison with material specification (wt\%)

\begin{tabular}{lrrrr}
\hline Element & Heat A & Heat B & Heat C & UNS S34700 spec. \\
\hline $\mathrm{Fe}$ & Bal. & Bal. & Bal. & Bal. \\
$\mathrm{Ni}$ & 10.46 & 10.68 & 9.80 & $9.00-13.00$ \\
$\mathrm{Cr}$ & 18.10 & 17.95 & 18.64 & $17.00-19.00$ \\
$\mathrm{Mn}$ & 1.63 & 1.34 & 1.83 & $2.00 \max$ \\
$\mathrm{Nb}$ & 0.96 & 0.70 & 0.81 & $10 \times \mathrm{C} \min , 1.00 \max$ \\
$\mathrm{Si}$ & 0.75 & 0.55 & 0.75 & $1.00 \max$ \\
$\mathrm{C}$ & 0.05 & 0.06 & 0.07 & $0.08 \max$ \\
$\mathrm{P}$ & 0.03 & 0.03 & 0.023 & $0.045 \max$ \\
$\mathrm{S}$ & 0.026 & 0.02 & 0.018 & $0.03 \max$ \\
\hline
\end{tabular}

Table 2.2 Fluence and estimated displacement damage distributions for two retrieved BFBs

\begin{tabular}{lrrr}
\hline \multirow{2}{*}{ Bolt \# } & \multicolumn{3}{c}{ Fluence $\left(10^{22} \mathrm{n} / \mathrm{cm}^{2}, \mathrm{E}>1 \mathrm{MeV}\right) /$ Estimated dpa } \\
\cline { 2 - 4 } & Head & Mid-shank & Mid-thread \\
\hline 4412 & $2.78 / 41$ & $2.27 / 34$ & $1.46 / 22$ \\
4416 & $1.91 / 29$ & $1.56 / 23$ & $1.00 / 15$ \\
\hline
\end{tabular}

The specimen machining plan and the schematic for specimen ID are shown in Figure 2.2 and Figure 2.3, respectively. For each BFB, four bend bar specimens and seven thin slice specimens have been machined. The bend bar specimens are planned for future fracture toughness and fatigue crack growth rate studies, whereas the thin slice specimens are planned for subscale tensile and microstructural analyses. Specimens were machined from different fluence regions of each bolt, allowing for studies of the effect of fluence on the microstructural and mechanical properties of BFBs. Three thin slice specimens were machined from the high-stress concentration region, i.e. the transition between the bolt head and shank, of each bolt to allow for further investigation of possible crack initiation sites. The IDs of specimens characterized in this study are summarized in Table 2.3

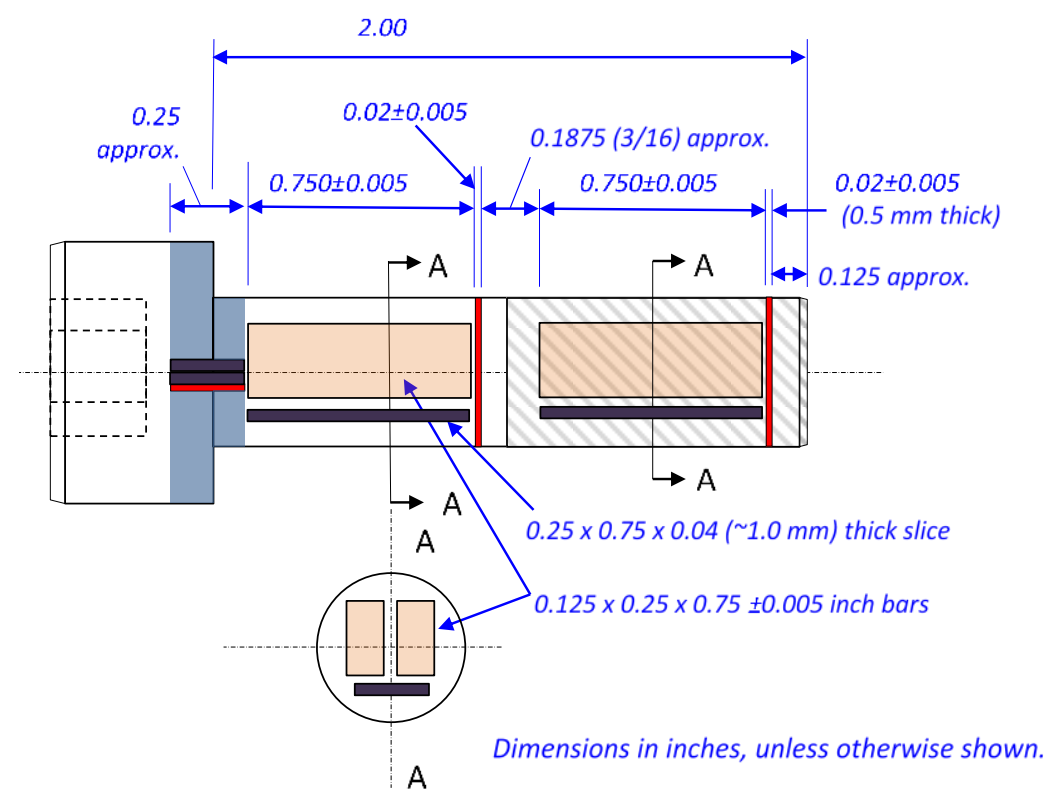

Figure 2.2 Machining diagram for the BFBs showing the color-coded sample types (red: $0.5 \mathrm{~mm}$ slices, black: $1.0 \mathrm{~mm}$ slices, light orange: bend bars, and light blue: remaining collar materials) [5] 


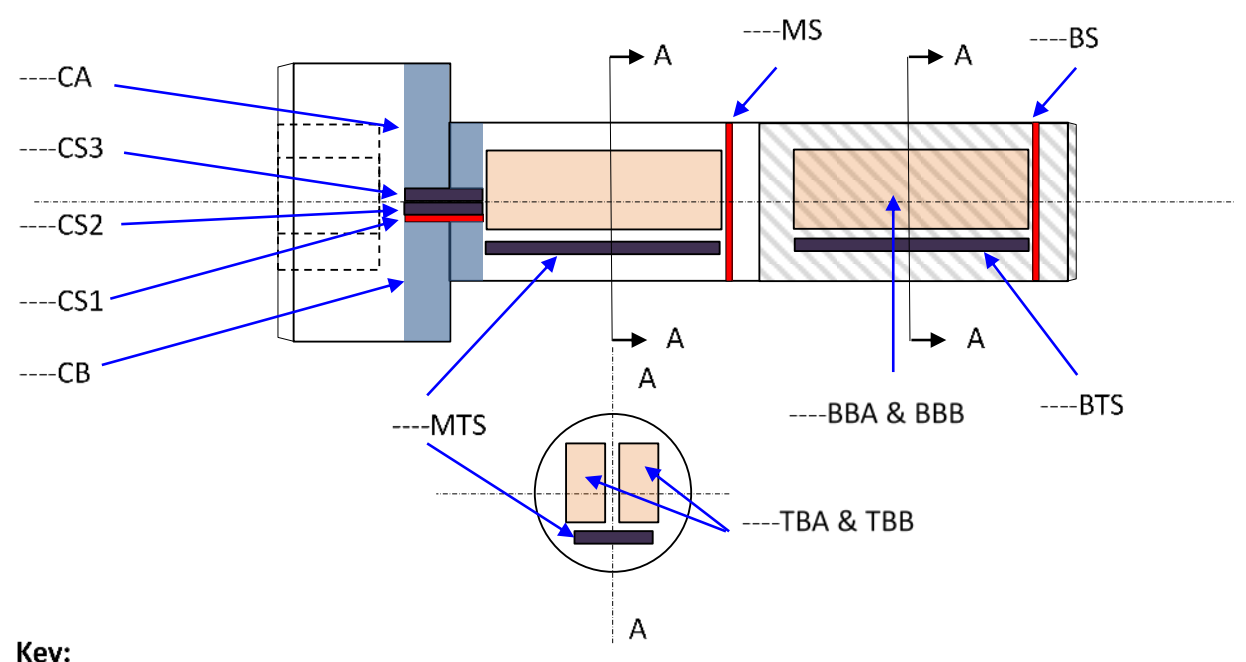

Key:

----: bolt number, CS: collar slice, CA \& CB: remaining collar materials, MS: middle slice, BS: bottom slice, MTS: middle thick slice, BTS: bottom thick slice, TBA \& TBB: top bend bar, BBA \& BBB: bottom bend bar

Figure 2.3 Schematic for sample IDs from machined BFBs [5]

Table 2.3 IDs of specimens characterized in this study

\begin{tabular}{lrrrrrr}
\hline \multirow{2}{*}{ Type of characterization } & \multicolumn{3}{c}{ Bolt 4412 } & \multicolumn{3}{c}{ Bolt 4416 } \\
\cline { 2 - 7 } & Head & Mid-shank & Mid-thread & Head & Mid-shank & Mid-thread \\
\hline TEM* & - & - & - & CS1 & MS & BS \\
STEM/EDS** & - & - & - & CS1 & MS & BS \\
Microhardness & CS2 & TBA & BBA & CS2 & TBA & BBA \\
\hline
\end{tabular}

*TEM: Transmission electron microscopy

**STEM/EDS: Scanning transmission electron microscopy/ Energy-dispersive X-ray spectroscopy

\subsection{METHODS}

Transmission electron microscopy (TEM) characterizations were performed on the thin slice specimens prepared by focused-ion-beam (FIB). In detail, after mechanically polished to mirror-surface conditions, thin slice specimens were loaded into an FEI Versa3D FIB/scanning-electron-microscope (SEM) DualBeam ${ }^{\mathrm{TM}}$ system, where lamella-type samples were lifted-out from the specimens for TEM characterizations. The TEM sample preparation followed the procedures of initial trenching, cutting, and thinning to $200 \mathrm{~nm}$ with $30 \mathrm{keV}$ Ga ion beam, rough polishing to $100 \mathrm{~nm}$ with ion beam energy gradually reduced from $16 \mathrm{keV}$ to 8 and $5 \mathrm{keV}$, and fine polishing with $2 \mathrm{keV}$ ion beam to remove most FIB-induced damage. Immediately before loading into the TEM, samples were always cleaned with a Fischione 1020 Plasma Cleaner for 3 to 5 mins.

Conventional TEM characterization of radiation-induced dislocation loops and cavities were conducted using a JOEL 2100F field-emission-gun TEM operated at $200 \mathrm{keV}$. Dislocation loops were imaged using the rel-rod dark-field (DF) technique [6]. Cavities were identified by comparing underfocused and overfocused images from the same area. This method provides high fidelity for quantification of cavity size and distributions.

Scanning transmission electron microscopy (STEM)/Energy-dispersive X-ray spectroscopy (EDS)-based mapping was performed using a Thermo (formerly FEI) Talos F200X 
scanning/transmission electron microscope equipped with the SuperX 4-sector X-ray energy dispersive spectrometer. Beam conditions were $1-2 \mathrm{nA}$ and $200 \mathrm{keV}$. X-ray spectrum images were acquired and then maps of the relevant $\mathrm{X}$-rays lines were extracted via post-processing [7].

Microhardness testing was performed using a Mitutoyo HV120 hardness tester in the hot cell environment. The test procedures were based on the ASTM E384 standard [8] using 0.5-1kgf load and $15 \mathrm{sec}$ dwell time. To evaluate the fluence and other potential effects, such as the variation of irradiation temperature, stress, etc. on materials irradiation hardening behavior, hardness measurements were performed across the entire surface area of each specimen. The detailed hardness measurement patterns are summarized in Figure 2.4.

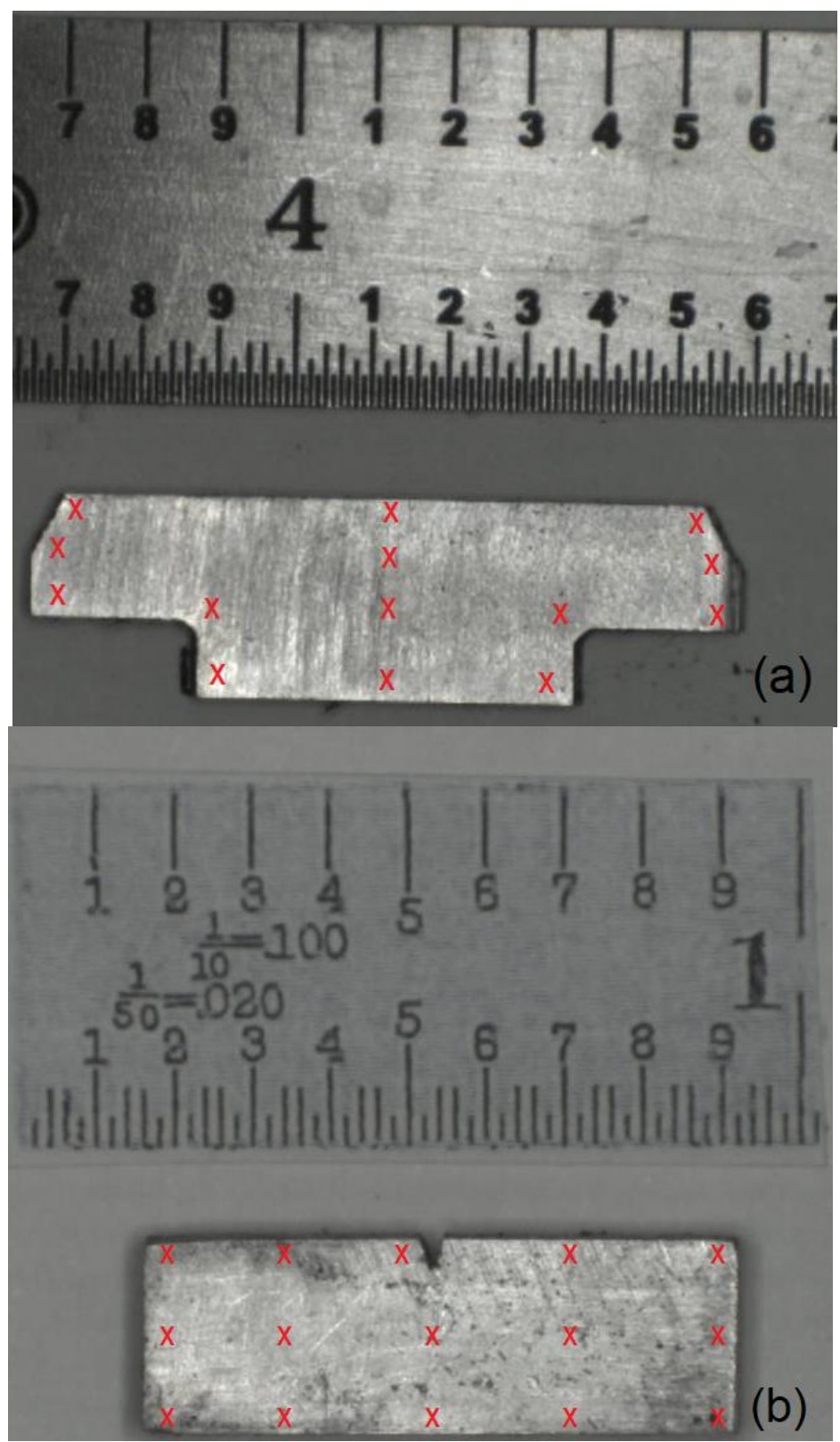

Figure 2.4 Hardness measurement patterns for 4412 CS2 and 4416 CS2 in (a) and 4412 TBA, 4412 BBA, 4416 TBA, and 4416 BBA in (b). At least three measurements were made at each marked location [4] 


\section{RESULTS}

\subsection{TEM CHARACTERIZATION}

TEM characterization revealed dislocation loops in 4416 CS1, MS, and BS samples. Figure 3.1 presents the images and statistics of dislocation loops in the three samples. Similar size distributions of the loops were observed for CS1 and MS samples. The loops grew larger in the BS sample, as demonstrated by the higher frequency of loops with a diameter larger than $24 \mathrm{~nm}$ shown in Figure 3.1(f). By analyzing more than 80 loops per sample, obtained from different areas, the average sizes and densities of loops were calculated and listed in Table 3.1. The sample thicknesses were measured using the electron energy loss spectroscopy (EELS) technique. In Table 3.1, the uncertainties in the size data are the standard deviation; the uncertainties in the density data are the standard deviation accounting both the variances in measured densities and thickness. The changes in loop density along the bolt length profile were insignificant compared with experimental errors. Lastly, no $\mathrm{NbC}$ was observed in the TEM characterization which may be due to the small size of FIB-prepared samples.
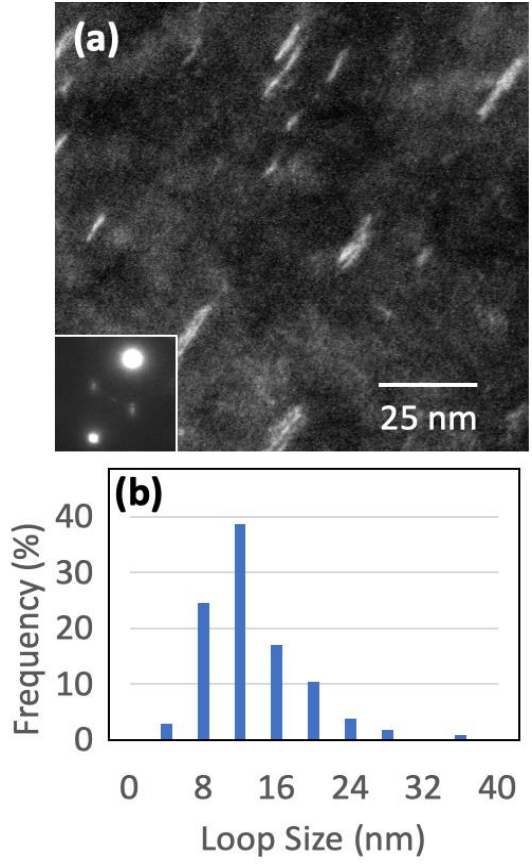

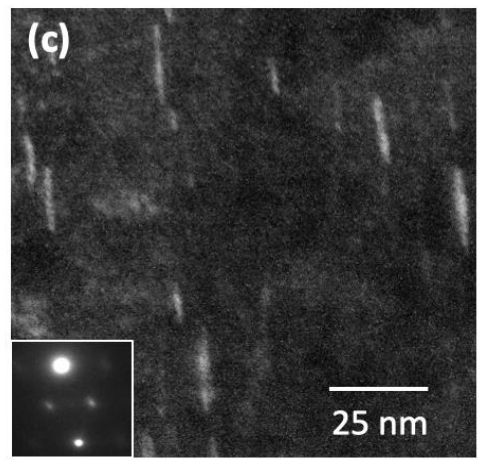

(d)

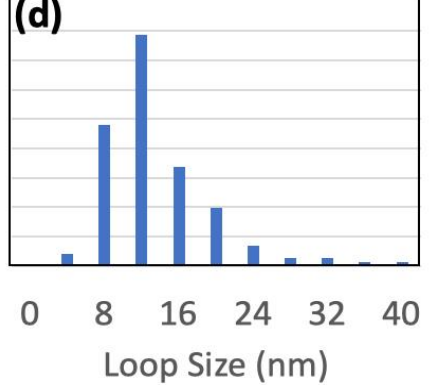

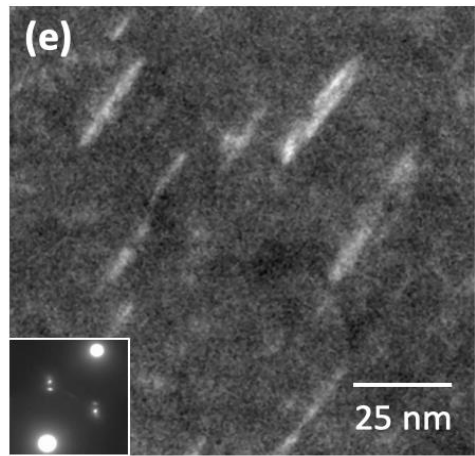

(f)

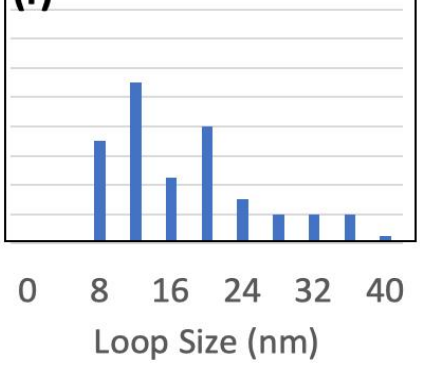

Figure 3.1 DF images of dislocation loops and their size distributions for 4416 CS1, MS, and BS samples presented in (a-b), (c-d), and (e-f), respectively

Table 3.1 Statistics of dislocation loops observed in TEM characterization of bolt 4416

\begin{tabular}{lrr}
\hline Sample & Size $(\mathrm{nm})$ & Density $\left(10^{22} / \mathrm{m}^{3}\right)$ \\
\hline CS1 & $11 \pm 5$ & $3 \pm 1$ \\
MS & $12 \pm 6$ & $4 \pm 2$ \\
BS & $16 \pm 8$ & $5 \pm 1$ \\
\hline
\end{tabular}

Besides dislocation loops, TEM characterization also revealed cavities in 4416 CS1, MS and BS specimens. Figure 3.2 shows cavities imaged at a focus of $-400 \mathrm{~nm}$ and Table 3.2 summarizes the statistical results of cavities. From the bolt head towards the thread end, the average cavity size increased with a decrease in cavity density. Most cavities observed in the 4416 CS1 sample had sub- 
nanometer sizes, which led to a very low swelling level, as shown in Table 3.2. On the other hand, cavities with diameters larger than $5 \mathrm{~nm}$ were observed in both $4416 \mathrm{MS}$ and BS samples, with the latter showing a higher frequency of larger cavities. The overall swelling levels for MS and BS samples were similar and larger than that of the CS1 sample.
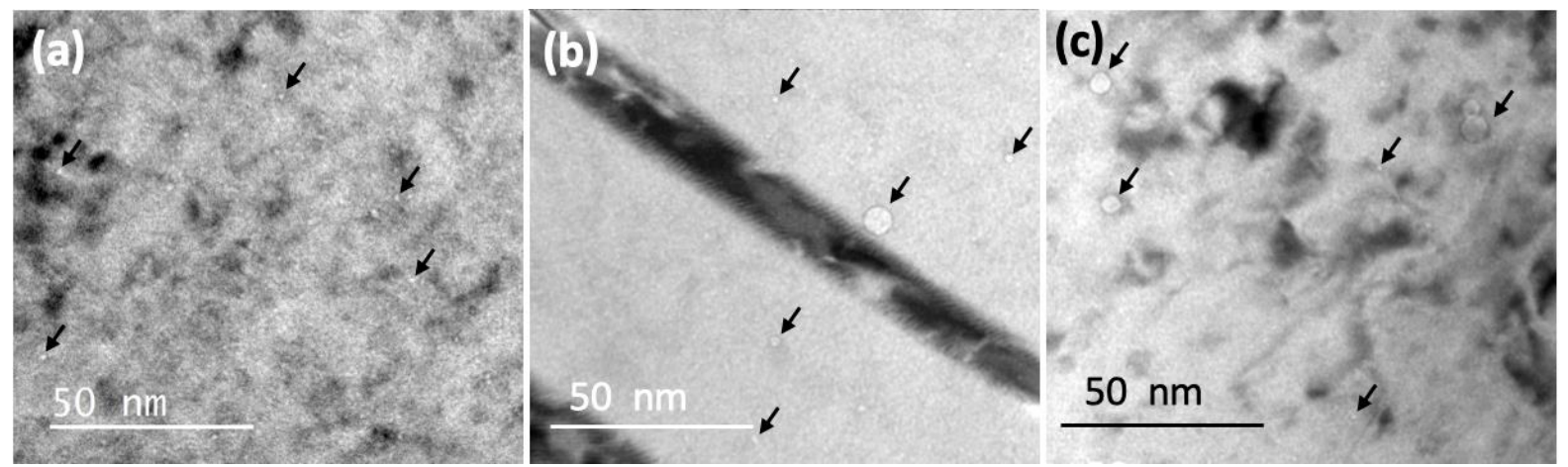

Figure 3.2 Cavities observed at an underfocused condition for the 4416 CS1 (a), MS (b), and BS (c) samples. Some of the cavities are marked with black arrows

Table 3.2 Statistics of cavities observed in TEM and the calculated swelling levels of bolt 4416

\begin{tabular}{lrrr}
\hline Sample & Size $(\mathrm{nm})$ & Density $\left(10^{22} / \mathrm{m}^{3}\right)$ & Swelling $(\%)$ \\
\hline CS1 & $0.9 \pm 0.9$ & $4.5 \pm 1.5$ & $0.003 \pm 0.002$ \\
MS & $1.4 \pm 1.0$ & $3.1 \pm 0.5$ & $0.02 \pm 0.01$ \\
BS & $1.8 \pm 1.3$ & $1.8 \pm 0.5$ & $0.02 \pm 0.01$ \\
\hline
\end{tabular}

\subsection{STEM/EDS CHARACTERIZATION}

STEM/EDS-based composition maps were acquired for $4416 \mathrm{CS} 1$, MS, and BS samples. As shown in Figure 3.3 to Figure 3.5, grain boundary (GB) segregation was observed in 4416 CS1 and MS, but not in $4416 \mathrm{BS}$, whereas fine precipitation was observed in all three samples. Intragranular precipitates with considerable densities showed enrichment in Ni and Si. For 4416 CS1 and MS samples, $\mathrm{Fe}, \mathrm{Cr}, \mathrm{Mn}$, and $\mathrm{S}$ were observed to be depleted from GBs, while Ni and $\mathrm{Si}$ were observed to be enriched on GBs. The segregation of P in the CS1 sample showed a dependence on GB characters. For example, the vertical GB in Figure 3.3 did not show $\mathrm{P}$ segregation, whereas $\mathrm{P}$ segregated on the vertical GB but not the horizontal GB in Figure 3.6. For the MS sample (Figure 3.4), P segregation was observed in all studied GBs. No NbC was observed in STEM/EDS maps which may be due to the small size of FIB-prepared samples. 


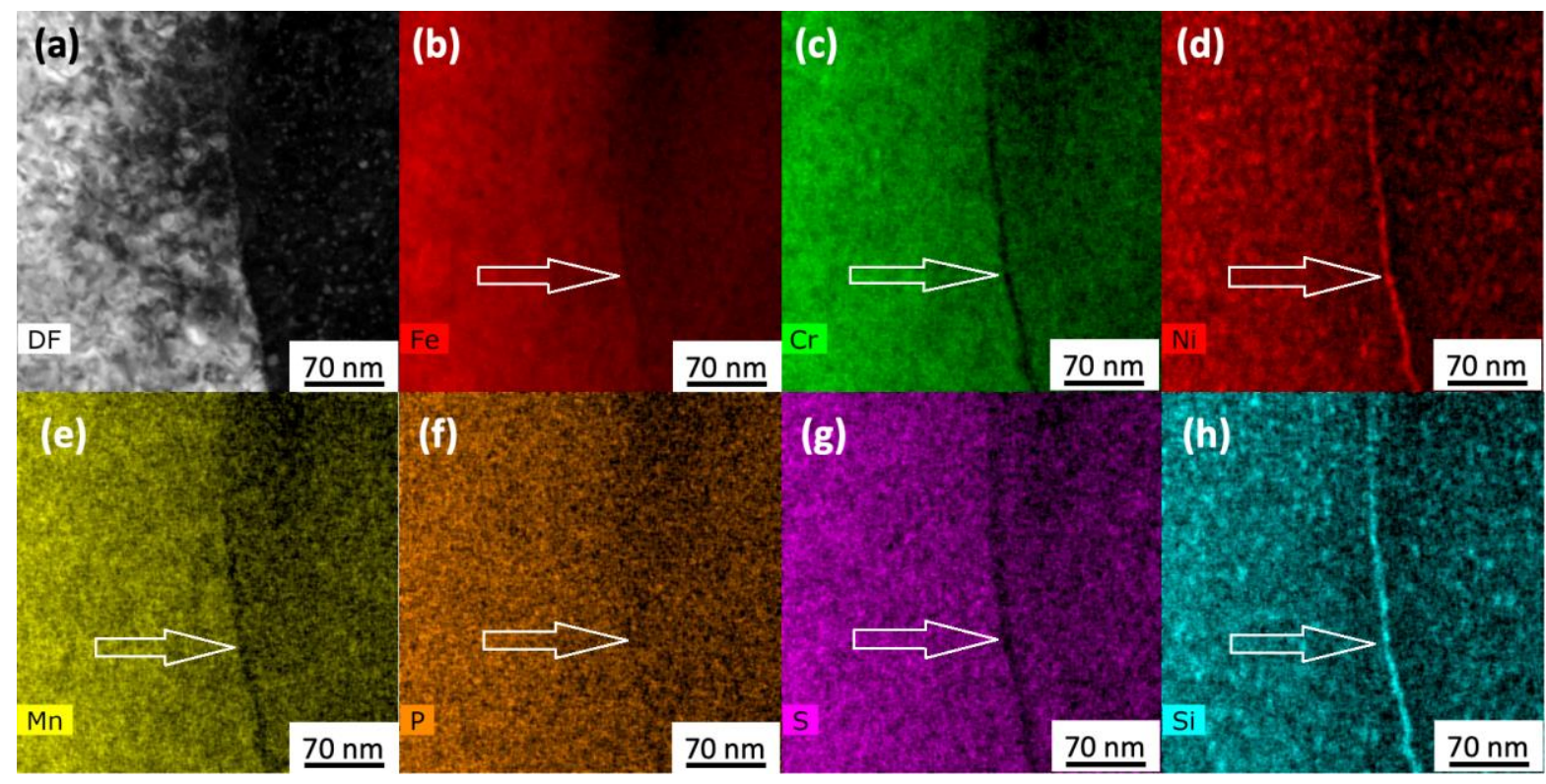

Figure 3.3 STEM/EDS-based composition maps for the 4416 CS1 sample. Arrows point to a GB

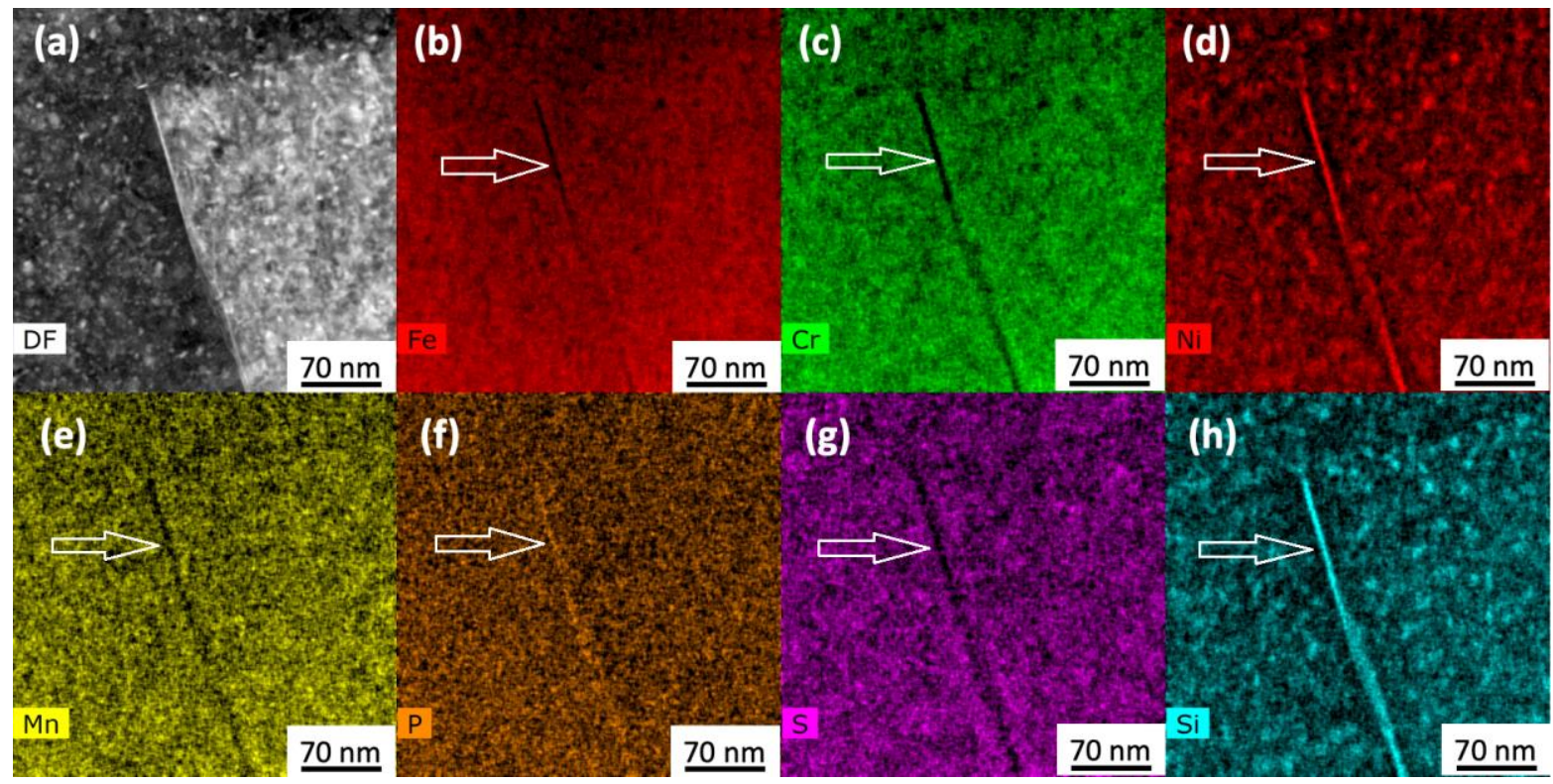

Figure 3.4 STEM/EDS-based composition maps for the 4416 MS sample. Arrows point to a GB 

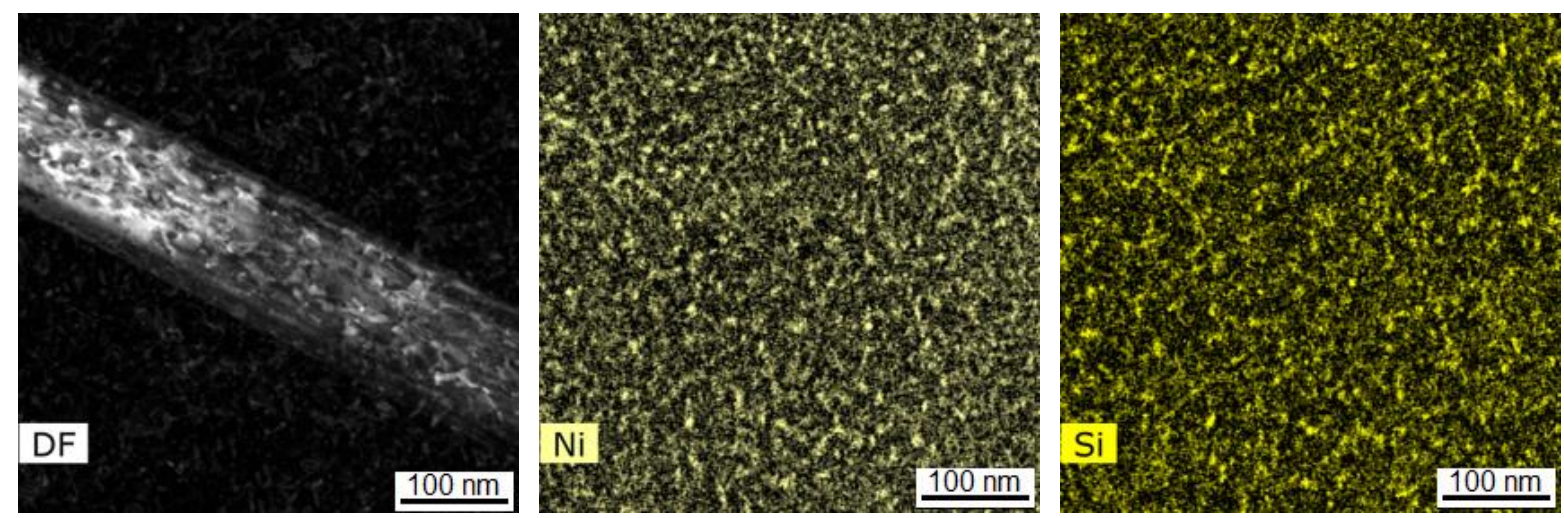

Figure 3.5 STEM/EDS-based composition maps showing Ni-Si precipitates in the 4416 BS sample
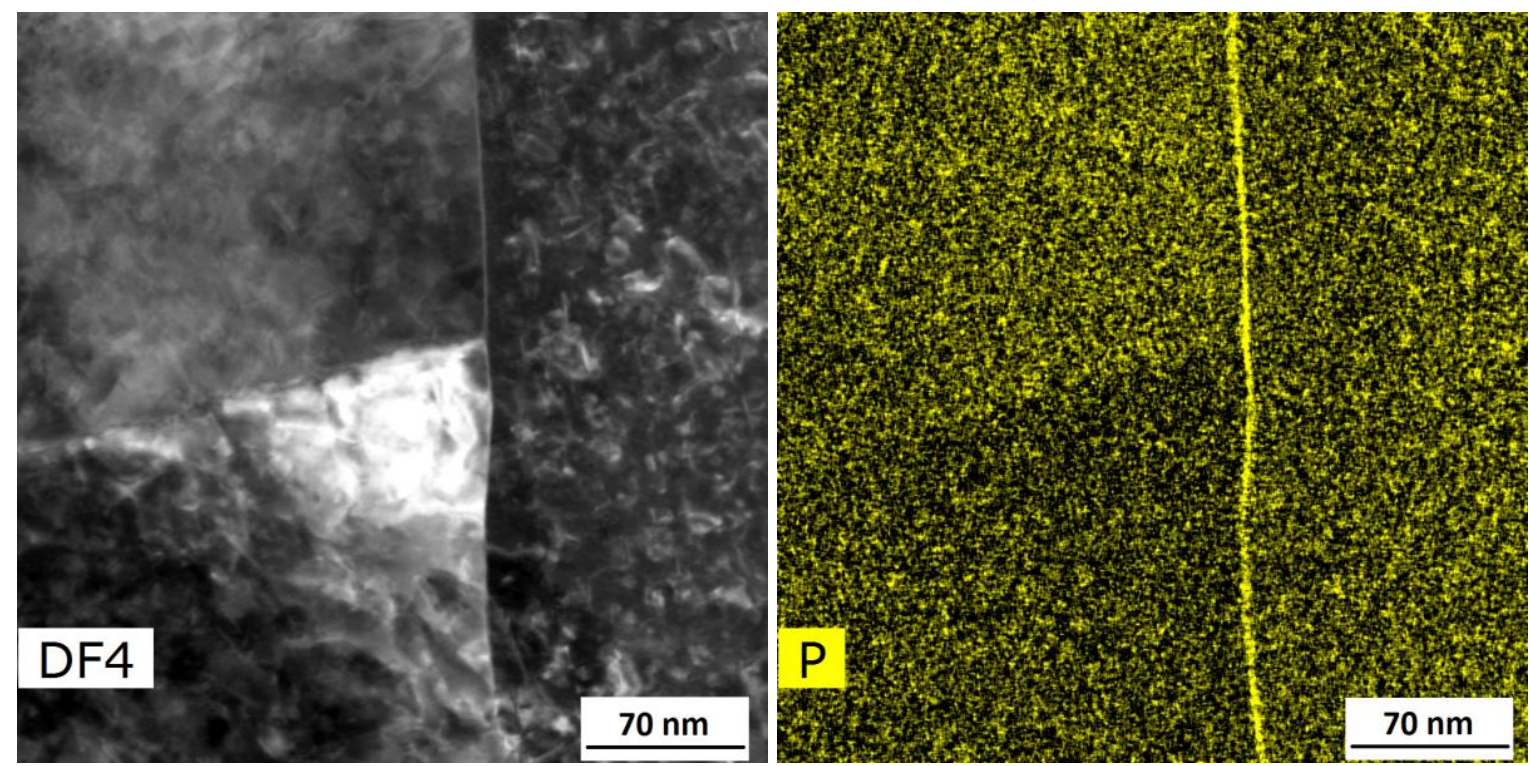

Figure 3.6 Segregation of P on the vertical GB, but not the horizontal GB of the 4416 CS1 sample

\subsection{MICROHARDNESS}

Microhardness results are combined with measurement coordinates to evaluate the spatial variation of hardness across the specimen surface. The results are shown in Figure 3.7 and Figure 3.8 for the bolt head thin slice and bolt shank and thread section bend bar specimens, respectively. Despite the spatial variation of hardness measurements for each specimen, no specific variation pattern was observed. Comparing hardness statistics results (Figure 3.9) reveals that for bolt 4412, hardness increased from the bolt head (high fluence region) towards the end of the thread section (low fluence region) whereas for bolt 4416, hardness variation was relatively small across the length of the bolt. 


\section{CS2}
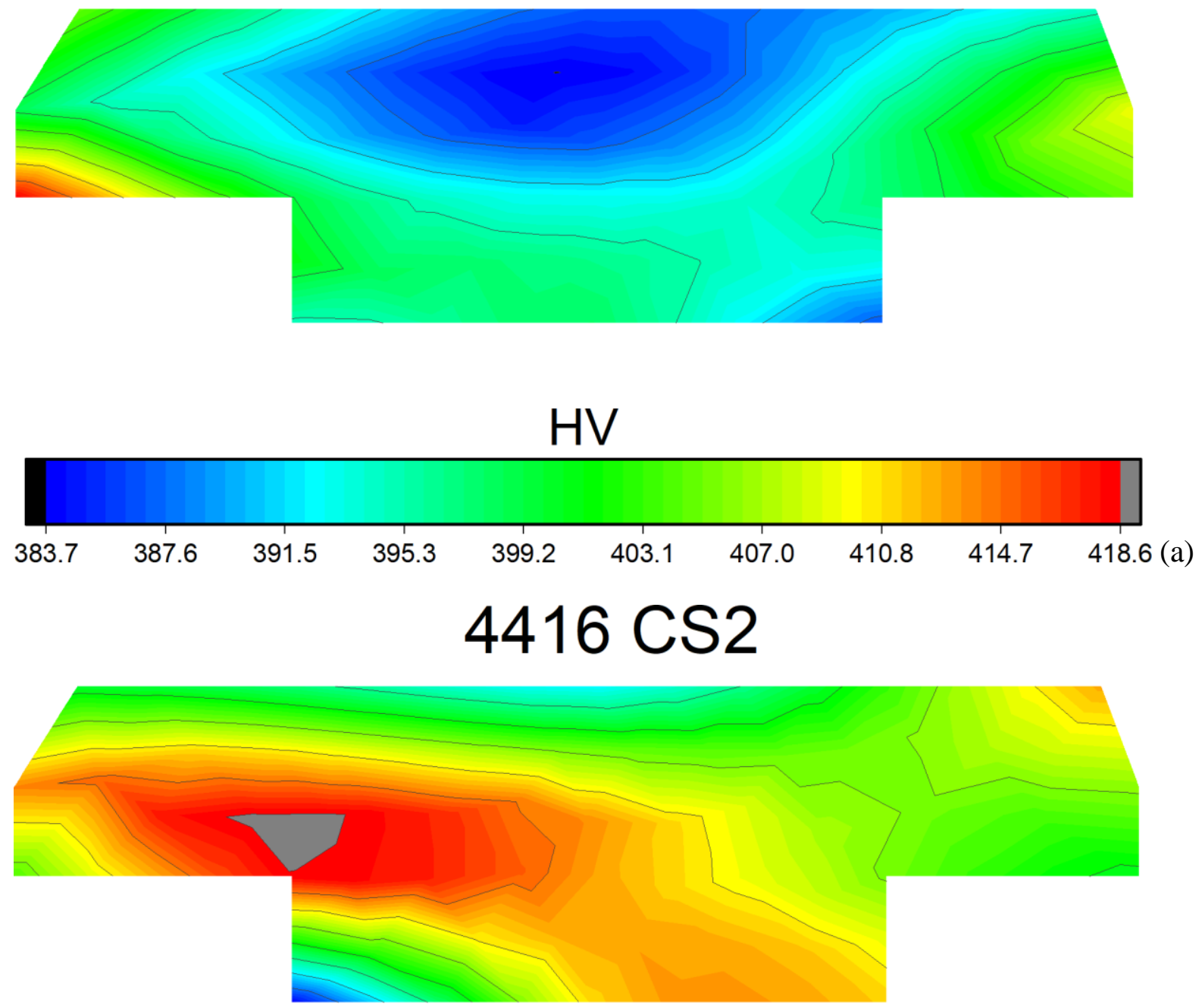

HV

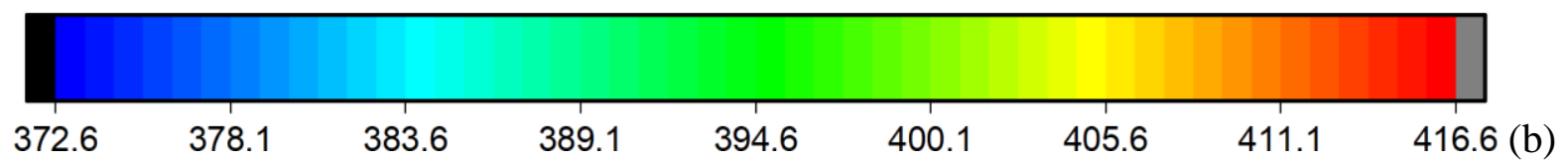

Figure 3.7 Microhardness maps for 4412 CS2 in (a) and 4416 CS2 in (b) 


\section{TBA}

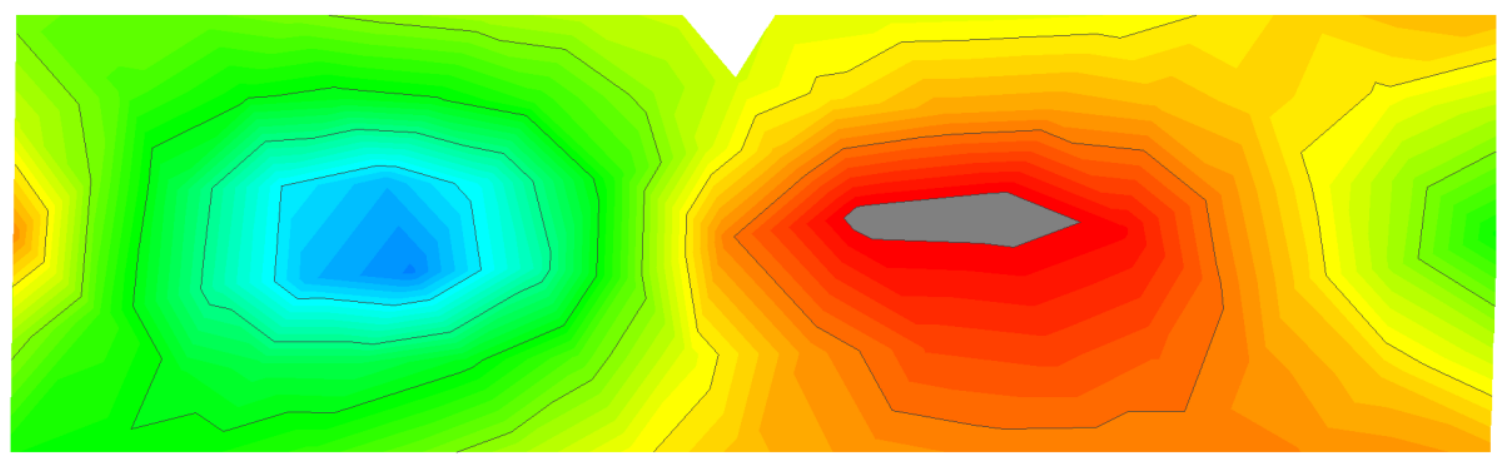

\section{HV}
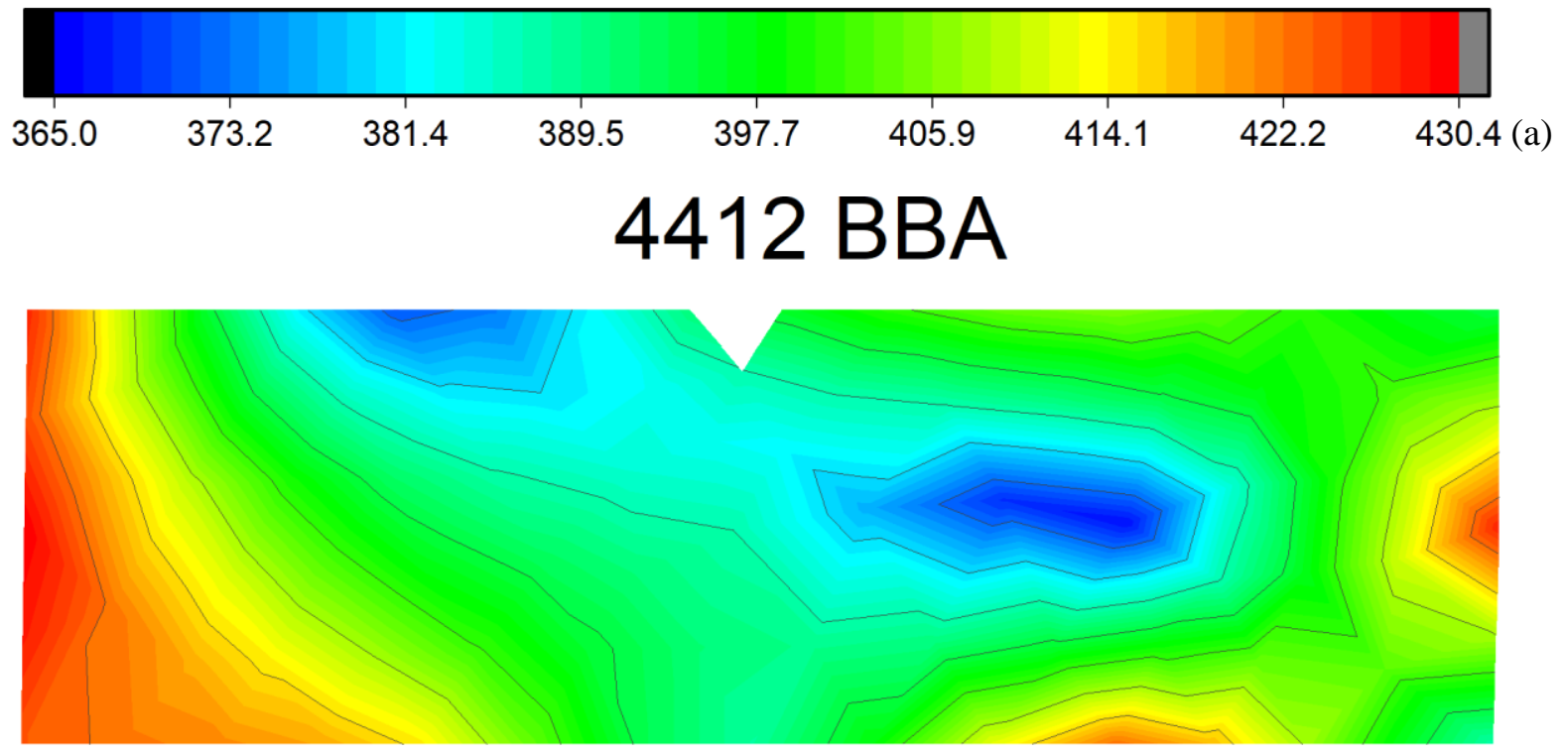

HV

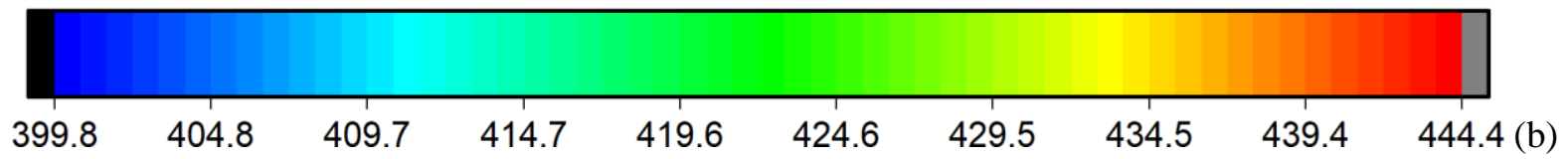




\section{TBA}

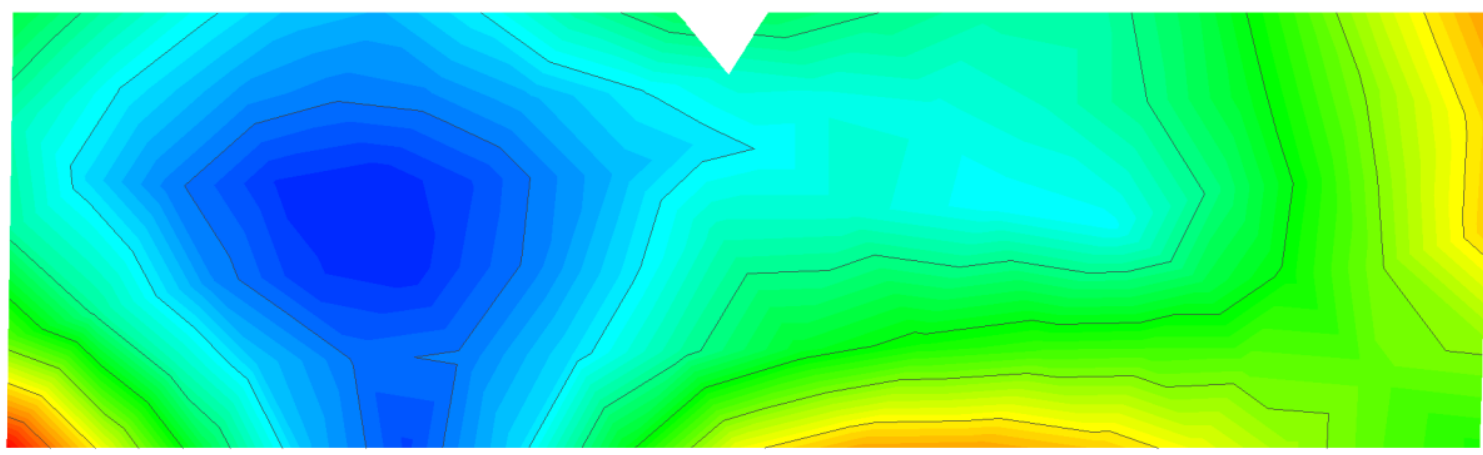

HV
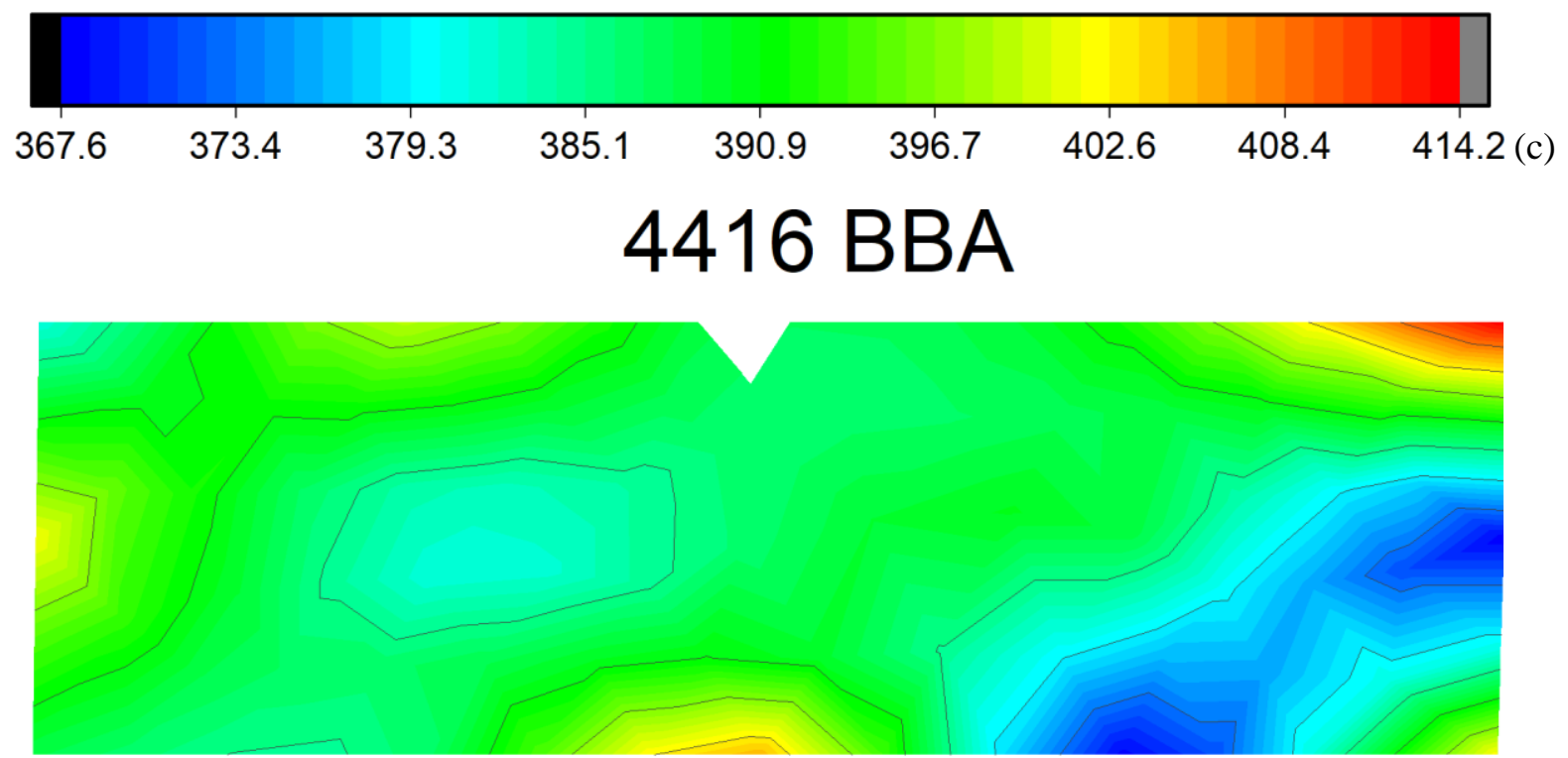

HV

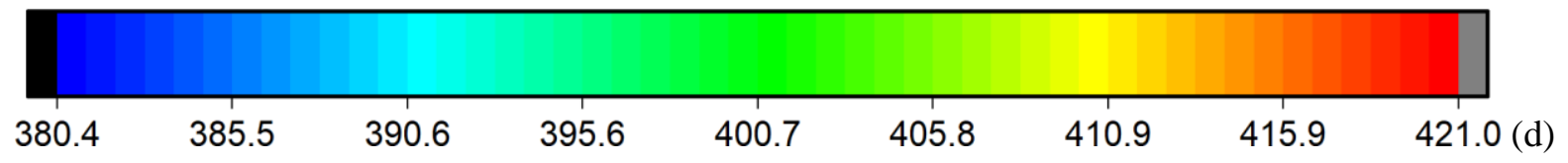

Figure 3.8 Microhardness maps for 4412 TBA in (a), 4412 BBA in (b), 4416 TBA in (c), and 4416 BBA in (d) 


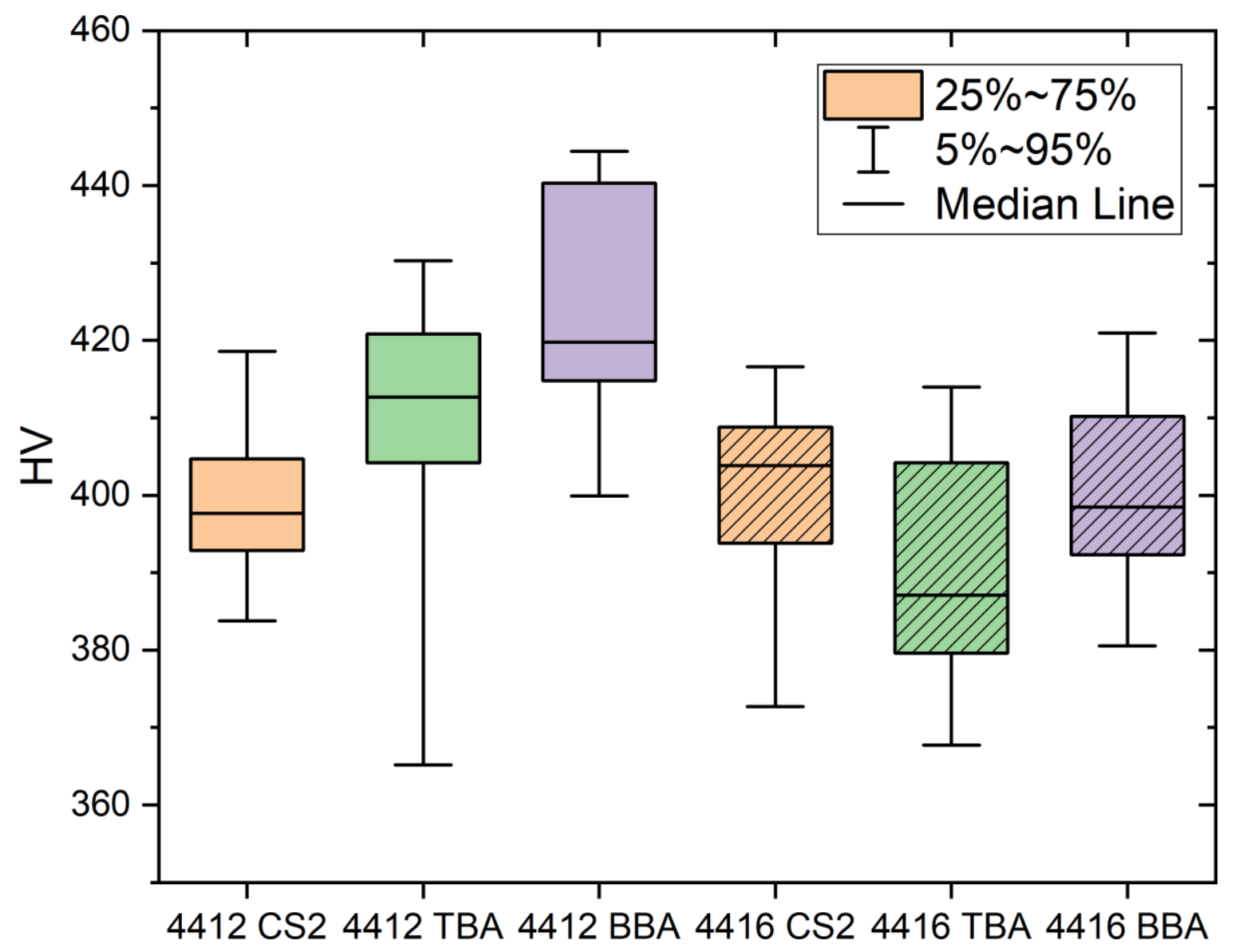

Figure 3.9 Statistics of microhardness measurements for bolts 4412 and 4416 


\section{DISCUSSION}

Frank loops rather than network dislocations were observed in 4416 CS1, MS, and BS samples. This agrees with changes in the microstructure of austenitic SS irradiated between 300 and $400^{\circ} \mathrm{C}$ as reported by Chopra [2] and Maziasz [9]. The size of dislocation loops is also within but close to the high end of 4-20 nm range in the work of Bruemmer et al. [10] for austenitic SS neutron-irradiated at temperatures higher than $300^{\circ} \mathrm{C}$. The observed number density of dislocation loops is lower than the reported value for types 304 and 316 SS irradiated in a boiling water reactor (BWR) at $275-300^{\circ} \mathrm{C}$ [11]. In general, an increase in irradiation temperature would increase the loop size while reducing their densities [12]. This confirms the irradiation temperature for bolt 4416 should be higher than $300^{\circ} \mathrm{C}$. In addition, the change of irradiation temperature during different reactor cycles can lead to microstructural changes not accounted for by simply considering a constant temperature [13]. Gamma heating can also influence the variations in the temperature across the length of the bolt and over the long service exposure time, this can create variations in microstructural features at the nano- to microscale. However, data are still sporadic from samples examined from commercial reactors as well as from research reactors. The variations occurring in the bolts that have been seen in this work and in previous studies can be difficult to compare to each other due to uncertainty in temperatures/irradiation conditions from both research and commercial reactor test data as well as error associated with data taking. Lastly, the development of dislocation loops during irradiation can also be influenced by the material initial microstructure and reactor operating conditions. For example, the cold work could delay the growth of Frank loops [9] and the stress during service could increase the mean loop size as well as their density under neutron irradiation [14].

Another distinctive microstructural feature after irradiation was cavity formation in 4416 CS1, MS, and BS samples as shown in Figure 3.2. The observed cavities were larger in MS and BS samples compared with the higher-dose CS1 sample, which was similar to the cavitation behavior of a cold worked type 316 SS BFB extracted from the Tihange PWR [13]. In that study, the bolt shank positions have higher irradiation temperatures in the range of $333-343^{\circ} \mathrm{C}$ than the irradiation temperature of the bolt head at $320^{\circ} \mathrm{C}$ [13]. The evolution of cavities is believed to be governed by the interactions between vacancies and gas contents of helium and hydrogen $[13,15]$. The coincidence in the growths of dislocation loops and cavities in the BS sample is consistent with vacancy emission from loops as an active loop growth mechanism [9], which led to a higher vacancy density in the matrix resulting in cavity growth [13]. This is also consistent with previous observations in neutron-irradiated stainless steels that the observed dislocation loops were interstitial loops [9]. Despite the cavities, swelling in 4416 CS1, MS, and BS samples was insignificant with maximum swelling of less than $0.02 \%$. The result is in line with a compilation of swelling measurements for PWR core internal components subjected up to 80 dpa dose [2].

Radiation-induced segregation (RIS) was observed in GBs of 4416 CS1 and MS samples as shown in Figure 3.3 and Figure 3.4. The segregated elements, such as $\mathrm{Ni}$ and $\mathrm{Si}$, and depleted elements, such as Fe, Cr, Mn, on GBs agrees with previously reported work [2]. However, RIS in GBs of the 4416 BS sample was not observed likely due to the small size of the FIB-prepared specimen. More investigation is needed to evaluate the RIS behavior in GBs of the $4416 \mathrm{BS}$ sample. In addition, RIS of $\mathrm{Ni}$ and $\mathrm{Si}$ to sinks led to the formation of Ni-Si clusters in the matrix of $4416 \mathrm{CS} 1$, MS, and BS samples. The possible phases for Ni-Si clusters are $\gamma^{\prime}\left(\mathrm{Ni}_{3} \mathrm{Si}\right)$ and $\mathrm{G}$ phase $\left(\mathrm{M}_{6} \mathrm{Ni}_{16} \mathrm{Si}_{7}\right)_{2}$ which needs to be confirmed by future study. In contrast to a common belief that minor elements, such as $\mathrm{S}$, should segregate to the boundary, depletion of S was observed on GBs for 4416 CS1 and MS samples in this study. Additional work is needed to understand the mechanism for $\mathrm{S}$ depletion on GBs. Further, $\mathrm{P}$ has the tendency to thermally segregate to GBs prior to irradiation. The segregation of $\mathrm{P}$ can be enhanced by irradiation [16-17]. However, measurements of grain boundary P segregation in neutron-irradiated SS have not yielded consistent results [2]. Indeed, in this study, P segregation on GBs was observed 
in the 4416 MS sample but only in one GB for the 4416 CS1 sample through the STEM/EDS survey of at least two GBs for each sample. Given the different irradiation conditions between the two samples, including but not limited to temperature, dose, gas content, stress [13, 15], and possible differences in the character of observed GBs, it is hard to determine the governing factor for P segregation via the current study. Future work to elucidate this topic will include quantification of segregation at more GBs and characterization of GB misorientation angles.

Radiation doses for 4416 CS1, MS, and BS samples have exceeded the typical saturation dose ( $\sim 5 \mathrm{dpa}$ ) for dislocation loops and RIS [2]. The fact that MS and BS samples exhibited more developed radiation-induced microstructural features, such as larger dislocation loops, cavities, and coarser precipitates than the CS1 sample indicated that the MS and BS samples experienced higher irradiation temperatures.

Lastly, materials irradiation hardening behavior was evaluated by microhardness measurements. Despite the extensive characterization efforts, there was no clear effect of neutron fluence on hardness values. The spatial variation of the hardness of each specimen also did not indicate any clear trend. Based on Ref. [2], the yield strength of the 300-series SSs irradiated at approximately $300^{\circ} \mathrm{C}$ appears to saturate at a neutron dose of 5 dpa. BFBs studied in this work all exceeded that dose limit and hence the effect of neutron fluence on hardness values may be limited and many other factors, such as irradiation temperature, materials initial properties, in-service conditions, etc. may affect the materials irradiation hardening behavior. 


\section{CONCLUSIONS}

Electron microscopy and microhardness characterization were performed on two high fluence type 347 stainless steels (SS) baffle former bolts (BFBs) retrieved from a commercial Westinghouse two-loop downflow type PWR. The radiation-induced defects in the material of this study are not considerably different from neutron-induced defects in 304/316 grades of SS. Results from this study fill the current knowledge gap in radiation-induced microstructure and mechanical property changes for type 347 austenitic SS after high fluence commercial PWR irradiation. Main findings of this study are:

1. Dislocation loops with average sizes in the range of 11-16 $\mathrm{nm}$ and number densities in the range of $3-5 \times 10^{22} / \mathrm{m}^{3}$ were observed from the retrieved BFB 4416 .

2. From bolt head to the end of the thread section, cavity size increased whereas the cavity number density decreased. The swelling of the BFB 4416 was insignificant with maximum swelling of less than $0.02 \%$.

3. Radiation-induced segregation (RIS) for BFB 4416 resulted in enrichment of $\mathrm{Ni}, \mathrm{Si}$, and $\mathrm{P}$ on grain boundaries but depletion of $\mathrm{Fe}, \mathrm{Cr}, \mathrm{Mn}$, and $\mathrm{S}$. In addition, Ni-Si clusters were observed in the matrix.

4. Radiation-induced microstructural features for BFB 4416 were more developed from the middle shank to the end of the thread section, e.g. larger dislocation loops, cavities, and coarser precipitates, indicating higher irradiation temperatures in those regions than in the bolt head.

5. Microhardness measurements did not show a clear effect of neutron fluence on hardness values or any specific spatial irradiation hardening pattern for BFBs 4412 and 4416. 


\section{REFERENCES}

[1] IAEA Technical Report, Stress Corrosion Cracking in Light Water Reactors: Good Practices and Lessons Learned, report number NP-T-3.13, International Atomic Energy Association, Vienna, Austria 2011.

[2] O. K. CHOPRA, Degradation of LWR Core Internal Materials due to Neutron Irradiation, NUREG/CR-7027 (2010).

[3] H. T. TANG, Materials Reliability Program Determination of Operating Parameters of Extracted Bolts (MRP-52), report number 1003076, EPRI technical report (2001).

[4] X. CHEN, K. J. LEONARD, M. A. SOKOLOV, M. A. BURKE, M. N. GUSSEV, S. R. CLARK, Specimen Fabrication from Two High Fluence Ginna Baffle Bolts, ORNL/TM-2017/455, August 25, 2017.

[5] K. J. LEONARD, M. A. SOKOLOV, M. N. GUSSEV, Post-Service Examination of PWR Baffle Bolts, Part I. Examination and Test Plan, Oak Ridge National Laboratory Report, ORNL/LTR2015/193, April 30, 2015.

[6] L. TAN, J. T. BUSBY, H. J. M. ChICHESTER, K. SRIDHARAN, T. R. ALLEN, Thermomechanical Treatment for Improved Neutron Irradiation Resistance of Austenitic Alloy (Fe21Cr-32Ni), J. Nucl. Mater. 437, 1-3, 70 (2013).

[7] C. M. PARISH, Multivariate Statistics Applications in Scanning Transmission Electron Microscopy X-ray Spectrum Imaging, Adv. Imag. Elect. Phys. 168, 249 (2011).

[8] ASTM E384-17, Standard Test Method for Microindentation Hardness of Materials, ASTM International, West Conshohocken, PA, 2017

[9] P. J. MAZIASZ, Overview of Microstructural Evolution in Neutron-irradiated Austenitic Stainless Steels, J. Nucl. Mater. 205, 118 (1993)

[10] S. M. BRUEMMER, E. P. SIMONEN, P. M. SCOTT, P. L. ANDRESEN, G. S. WAS, J. L. NELSON, Radiation-induced Material Changes and Susceptibility to Intergranular Failure of LightWater-Reactor Core Internals, J. Nucl. Mater. 274, 3, 299 (1999)

[11] D. EDWARDS, E. SIMONEN, S. BRUEMMER, P. EFSING, Microstructural Evolution in Neutron-irradiated Stainless Steels: Comparison of LWR and Fast-Reactor Irradiations, Proc. 12th Intl. Conf. on Environmental Degradation of Materials in Nuclear Power System - Water Reactors, Salt Lake City, Utah, August 14-18, 2005, 419, Minerals, Metals, \& Materials Society (2005)

[12] P. J. MAZIASZ, Effects of Helium Content of Microstructural Development in Type 316 Stainless Steel under Neutron Irradiation, ORNL-6121, ORNL report (1985)

[13] D. J. EDWARDS, E. P. SIMONEN, F. A. GARNER, L. R. GREENWOOD, B. M. OLIVER, S. M. BRUEMMER, Influence of Irradiation Temperature and Dose Gradients on the Microstructural Evolution in Neutron-irradiated 316SS, J. Nucl. Mater. 317, 1, 32 (2003)

[14] H. R. BRAGER, F. A. GARNER, G. L. GUTHRIE, The Effect of Stress on the Microstructure of Neutron Irradiated Type 316 Stainless Steel, J. Nucl. Mater. 66, 3, 301 (1977)

[15] F. A. GARNER, E. P. SIMONEN, B. M. OLIVER, L. R. GREENWOOD, M. L. GROSSBECK, W. G. WOLFER, P. M. SCOTT, Retention of Hydrogen in FCC Metals Irradiated at Temperatures Leading to High Densities of Bubbles or Voids, J. Nucl. Mater. 356, 1-3, 122 (2006)

[16] B. A. GUROVICH, E. A. KULEShOVA, Ya. I. SHTROMBAKH, O. O. ZABUSOV, E. A. KRASIKOV, Intergranular and Intragranular Phosphorus Segregation in Russian Pressure Vessel 
Steels due to Neutron Irradiation, J. Nucl. Mater. 279, 2-3, 259 (2000)

[17] Z. JIAO, G. S. WAS, Novel Features of Radiation-induced Segregation and Radiation-induced Precipitation in Austenitic Stainless Steels, Acta. Mater. 59, 3, 1220 (2011) 